Prepared in cooperation with the U.S. Environmental Protection Agency

\title{
Collection of Pyrethroids in Water and Sediment Matrices: Development and Validation of a Standard Operating Procedure
}

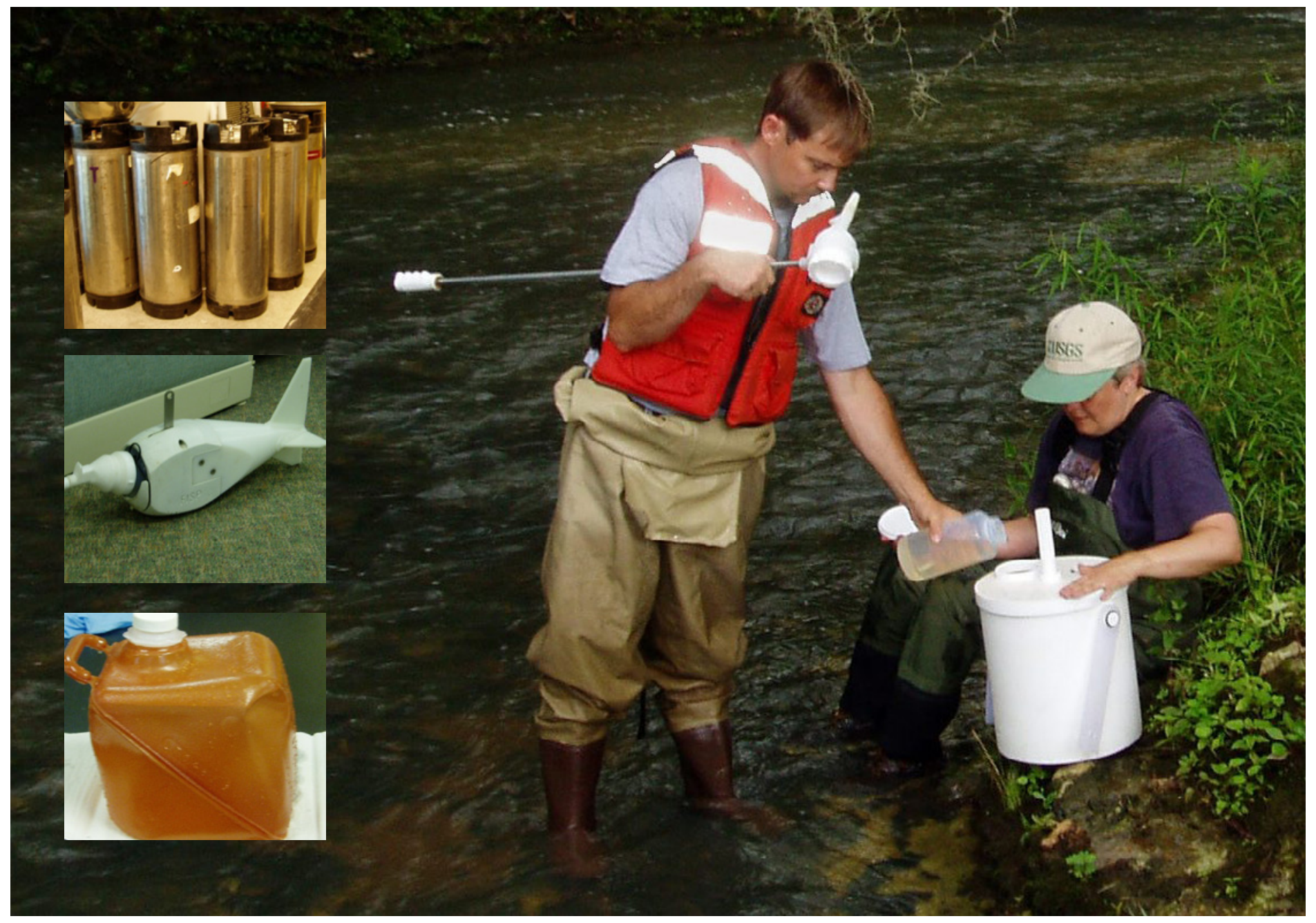

Scientific Investigations Report 2009-5012 
Cover: Demonstrating the use of a churn sampler, 2005. (Photograph taken by Mark Sandstrom, U.S. Geological survey.) 


\section{Collection of Pyrethroids in Water and Sediment Matrices: Development and Validation of a Standard Operating Procedure}

By Michelle L. Hladik, James L. Orlando, and Kathryn M. Kuivila

Prepared in cooperation with U.S. Environmental Protection Agency

Sciencific Investigations Report 2009-5012 


\title{
U.S. Department of the Interior \\ KEN SALAZAR, Secretary
}

\author{
U.S. Geological Survey \\ Suzette M. Kimball, Acting Director
}

U.S. Geological Survey, Reston, Virginia: 2009

For more information on the USGS - the Federal source for science about the Earth, its natural and living resources, natural hazards, and the environment, visit http://www.usgs.gov or call 1-888-ASK-USGS

For an overview of USGS information products, including maps, imagery, and publications, visit http://www.usgs.gov/pubprod

To order this and other USGS information products, visit http://store.usgs.gov

Any use of trade, product, or firm names is for descriptive purposes only and does not imply endorsement by the U.S. Government.

Although this report is in the public domain, permission must be secured from the individual copyright owners to reproduce any copyrighted materials contained within this report.

Suggested citation:

Hladik, M.L., Orlando J.L., and Kuivila, K.M., 2009, Collection of pyrethroids in water and sediment matrices: development and validation of a standard operating procedure: U.S. Geological Survey Scientific Investigations Report 2009-5012, 22 p. Available at http://pubs.usgs.gov/sir/2009/5012/ 


\section{Acknowledgments}

We would like to thank Debra Denton, Patti Tenbrook, John Zimmerman and Brian Schumacher of the U.S. Environmental Protection Agency (USEPA) for their technical guidance. Dave Crane, California Department of Fish and Game, and Li-Ming He, California Department of Pesticide regulation, provided assistance in reviewing the report. 
This page intenionally left blank. 


\section{Contents}

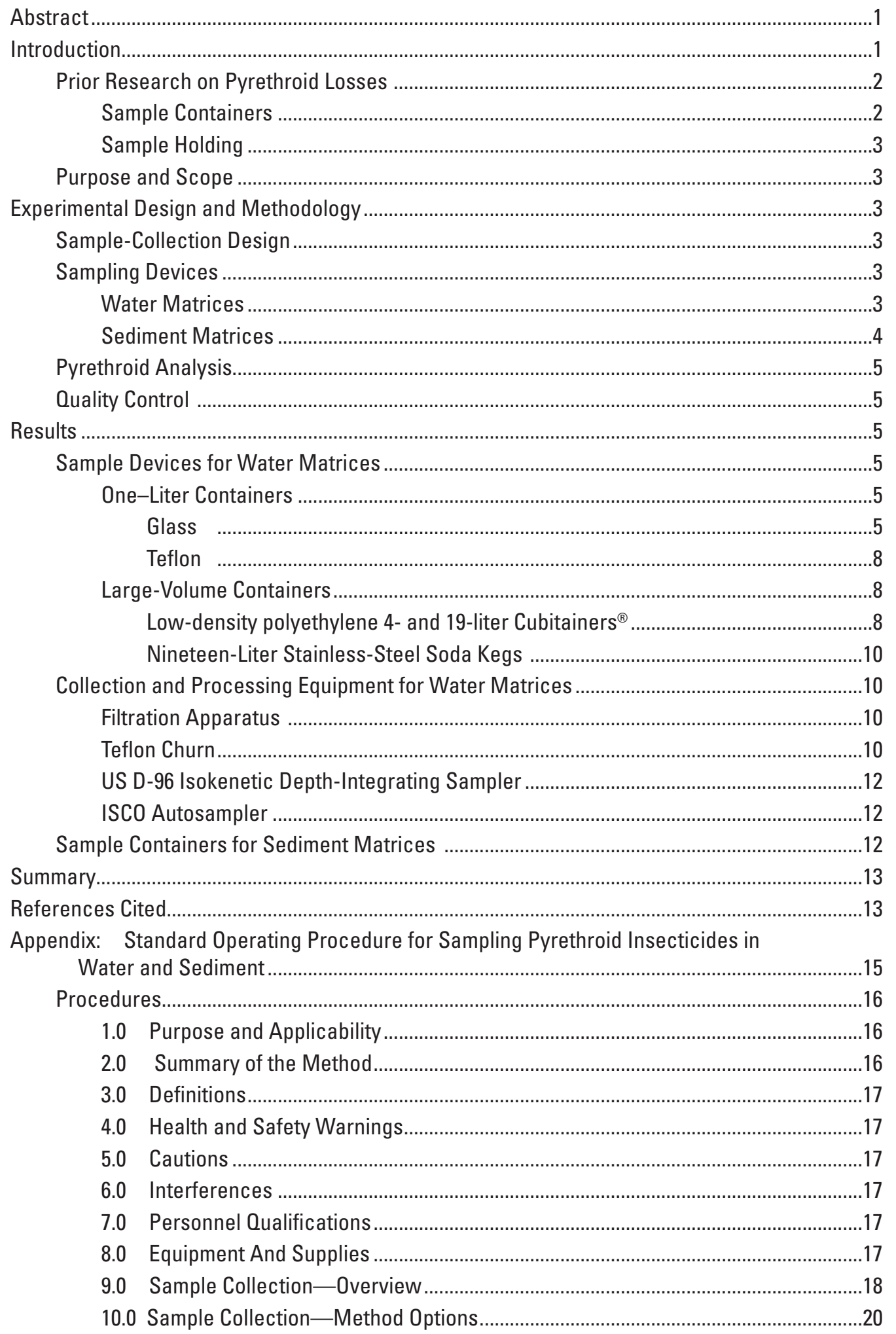




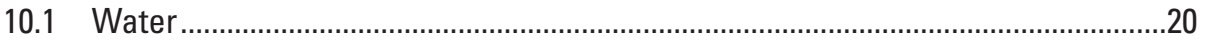

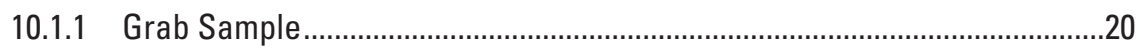

10.1.2 Isokinetic Depth-Integrated Sample …………….........................................

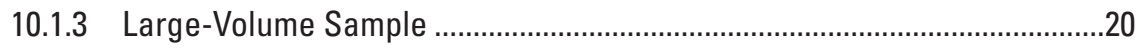

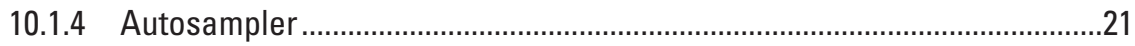

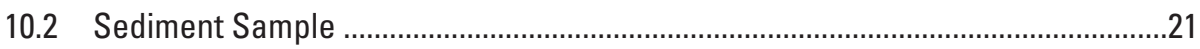

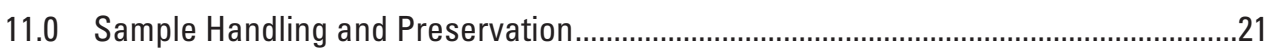

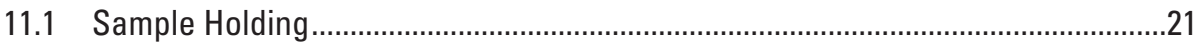

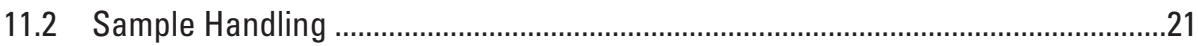

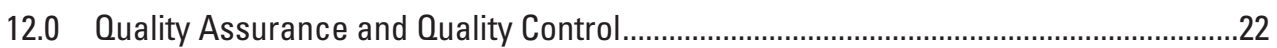

\section{Figures}

Figure 1. Fraction of pyrethroids associated with 1-liter glass bottle walls..................................

Figure 2. Fraction of pyrethroids associated with 1-liter glass bottles at two different concentrations.

Figure 3. Fraction of pyrethroids associated with 1-liter glass bottles with varying DOC ............8

Figure 4. Fraction of pyrethroids associated with 1-liter glass and Teflon bottles.........................9

Figure 5. Fraction of pyrethroids associated with 1-liter Teflon bottles ........................................

Figure 6. Fraction of pyrethroids left in the filtration pump ........................................................

Figure 7. Fraction of pyrethroids associated with the churn walls..............................................11

\section{Tables}

Table 1. Summary of devices tested for pyrethroid losses for water samples

Table 2. Comparison of the project quality-assurance/quality control (OA/OC) plan with the Surface Water Ambient Monitoring Program (SWAMP) quality-control requirements for organic constituents (pesticides) in water and sediment

Table 3. Loss of pyrethroids to 4 -liter and 19-liter Cubitainers ${ }^{\circledR}$, and to 19-liter stainless-steel soda kegs

Table 4. Losses of pyrethroids to 3-liter Teflon bags ..............................................................12

Table 5. Losses of pyrethroids from sediment to 500-milliliter glass jars .....................................12

Appendix Table A1. Range of percent of 14 pyrethroid compounds spiked in environmental samples and exposed to various sampling equipment/container materials 


\title{
Abbreviations and Acronyms
}

(Additional information or clarification given in parentheses)

Brij-35, polyoxyethyleneglycol dodecyl ether

DCM, dichloromethane

DOC, dissolved organic carbon

EPA, U.S. Environmental Protection Agency

FEP, fluorinated ethylene polypropylene

GC/MS, gas chromatography-mass spectrometry

HDPE, high-density polyethylene

i.d., inner diameter

LDPE, low-density polyethylene

nd, not detected

PEG, polyethylene glycol

PTFE, polytetrafluoroethylene

PVC, polyvinylchloride

rpm, revolutions per minute

$\mathrm{SD}$, standard deviation

SOP, standard operating procedure

SPE, solid-phase extraction

SRM, standard reference material

SSC, suspended-solids concentration

SWAMP, Surface Water Ambient Monitoring Program (California)

USGS, U.S. Geological Survey

\section{Units of Measurement}

\author{
$\mathrm{cm}$, centimeter \\ g, gram \\ L, liter \\ L/min, liter per minute \\ $\mathrm{lb}$, pound \\ $\mathrm{m}$, meter \\ $\mu \mathrm{g} / \mathrm{L}$, micrograms per liter \\ $\mu \mathrm{L}$, microliter \\ $\mathrm{mg}$, milligram \\ $\mathrm{mg} / \mathrm{L}$, milligram per liter \\ $\mathrm{mL}$, milliliter \\ $\mathrm{mL} / \mathrm{cm}^{2}$, milliliters per square centimeter \\ $\mathrm{mL} / \mathrm{min}$, milliliter per minute \\ $\mathrm{mm}$, millimeter \\ $\mathrm{mM}$, millimolar \\ ng, nanogram \\ $\mathrm{ng} / \mathrm{g}$, nanogram per gram \\ $\mathrm{ng} / \mathrm{L}$, nanogram per liter \\ $\mathrm{ng} / \mu \mathrm{L}$, nanogram per microliter
}

\section{Notes}

Temperature in degrees Celsius $\left({ }^{\circ} \mathrm{C}\right)$ may be converted to degrees Fahrenheit $\left({ }^{\circ} \mathrm{F}\right)$ as follows:

$$
{ }^{\circ} \mathrm{F}=\left(1.8 \times{ }^{\circ} \mathrm{C}\right)+32
$$

Chemical concentrations in water are reported in units of nanograms per liter (ng/L). Chemical concentrations in sediment are reported in units of nanograms per gram of dry weight sediment (ng/g).

Use of liter (L) as a special name for cubic decimeter (dm3) is restricted to the measurement of liquids and gases. 
This intentionally left blank. 


\title{
Collection of Pyrethroids in Water and Sediment Matrices: Development and Validation of a Standard Operating Procedure
}

\author{
By Michelle L. Hladik, James L. Orlando, and Kathryn M. Kuivila
}

\begin{abstract}
Loss of pyrethroid insecticides onto surfaces during sample collection can confound the interpretation of analytical and toxicity test results. Sample collection devices, container materials, and water matrix composition have a significant influence on the association of pyrethroids to container walls, which can be as high as 50 percent. Any sample collection method involving transfer through multiple containers or pieces of equipment increases the potential for pyrethroid loss. This loose "surface-association" with container walls can be reversed through agitation. When sampling water matrices with pumps or autosamplers, no pyrethroids were lost as long as the water was moving continuously through the system. When collecting water matrices in containers, the material with the least amount of pyrethroid sorption is as follows: glass less than $(<)$ plastic less than $(<)$ Teflon. Additionally, pyrethroids were easier to re-suspend from the glass container walls. Since the amount of surface-association is proportional to the ratio of volume-to-contact-area of the sample, taking larger-volume field samples (greater than 3 liters) reduced pyrethroid losses to less than 10 percent. The amount of surface-association cannot be predicted easily because of the dependence on water matrix composition; samples with higher dissolved organic carbon or suspended-sediment concentrations were observed to have lower percent loss. Sediment samples were not affected by glass-container sorption (the only containers tested). Standardized sample-collection protocols are critical to yield accurate pyrethroid concentrations for assessment of potential effects, and have been summarized in an accompanying standard operating procedure.
\end{abstract}

\section{Introduction}

Pyrethroids have replaced diazinon and chlorpyrifos as the most common insecticides in agricultural areas and the urban marketplace (California Department of Pesticide Regulation, 2005; TDC Environmental, 2005). Because pyrethroids are highly toxic to aquatic organisms, and because researchers have detected pyrethroids in surface waters and (more frequently) in sediments, they must be able to be accurately measured in the environment (TDC Environmental, 2008).

Pyrethroids are known from previous research to "associate" with container surfaces, but the extent of their association has not been tested with respect to field sampling devices. The loss of pyrethroids to surfaces is labeled as an "association" because the process is reversible and the compounds do not chemically "bind" to the surfaces. Sample-collection devices, sample-collection and laboratory-container material, container size, holding conditions, and sample-handling procedures have been found by researchers to have significant influences on the losses of pesticides onto container walls (see section called "Sample Containers" of this report). Determining the optimum sample-collection procedures for minimizing association of pyrethroids to container and sampling-equipment surfaces, and disseminating a validated standard operating procedure (SOP), helps ensure that consistent and technically sound methods are available for sample collection and handling. 


\section{Prior Research on Pyrethroid Losses}

The following summarizes prior published literature about the association of aqueous pyrethroids. This includes pyrethroid association to sample containers, and the effects of hold time.

\section{Sample Containers}

For many years, researchers have observed that a significant fraction of pyrethroids can associate to sample containers, and thereby complicate analysis. Sharom and Solomon (1981) noted that when trying to perform bioassays with glass or plastic containers, permethrin showed a significant amount of loss. Glass scintillation vials containing 5, 10, and $20 \mathrm{~mL}$ of water, with volume-to-contact-area ratios of $0.32,0.38$, and $0.44 \mathrm{~mL} / \mathrm{cm}^{2}$, had permethrin losses of 70, 63, and 42 percent (after 48 hours), respectively. The data showed that an increase in the volume-to-contact-area ratio was associated with a decrease in pyrethroid loss. Other researchers have noted similar behavior of pyrethroids. In studies using $30-\mathrm{mL}$ glass centrifuge tubes, approximately 60 percent of $\lambda$-cyhalothrin and tefluthrin in water was associated to the container (Zhou and others, 1995; 1997). Lee and others (2002) found a 36-percent loss of permethrin to a 1-L glass bottle, (volume-to-contactarea ratio of $0.62 \mathrm{~mL} / \mathrm{cm}^{2}$, converted from $1.6 \mathrm{~cm}^{2} / \mathrm{mL}$ in the original paper), agreeing well with Sharom and Solomon (1981). Association losses similar to permethrin were found for bifenthrin and deltamethrin, with all three pyrethroids tested reaching equilibrium within 24 hours (Lee and others, 2002). Wheelock and others (2005), using 1-L glass bottles, found that approximately 20 percent of $\lambda$-cyhalothrin in water remained on the container walls after 24 hours. Pyrethroid association was less than that observed by Lee and others (2002), but the time to reach equilibrium was the same (24 hours).

Plastic containers also have been tested for pyrethroid losses. Polyethylene, polyvinylchloride (PVC), and Teflon showed 60, 50, and 25 percent loss, respectively, after 120 hours ( $15 \mathrm{~mL}$ of water in a $20-\mathrm{mL}$ scintillation vial) (Sharom and Solomon, 1981). Another study, using sample containers made of Teflon, high-density polyethylene (HDPE), and glass, found that values of aqueous pyrethroids associated to the walls of the $20-\mathrm{mL}$ beakers were ranked highest to lowest as Teflon greater than (>) HDPE greater than (>) glass (Wheelock and others, 2005). Furthermore, this study also explored $400-\mathrm{mL}$ polycarbonate and $400-\mathrm{mL}$ glass beakers. Initially the polycarbonate had less loss of $\lambda$-cyhalothrin to the container walls compared to glass, but after 24 hours, more was lost to the polycarbonate surface than to the glass. Polytetrafluoroethylene (PTFE) bottles $(100 \mathrm{~mL})$ retained more pyrethroids than did glass bottles of the same size; for cypermethrin, fenvalerate, and permethrin, the amount retained on the bottle walls was 90-95 percent for PTFE and 70-95 percent for glass after 66 hours (House and Ou, 1992).
The loss of aqueous pyrethroids to sample containers is sometimes reversible, suggesting that the loss from solution may not be caused by chemisorption. Sharom and Salomon (1981) demonstrated that permethrin could be re-suspended in solution from glass and Teflon, but not from polyethylene and PVC. Lee and others (2002) noted that vigorous shaking of bottles prior to analysis did not result in complete resuspension of pyrethroids; however, shaking resulted in less pyrethroid loss to container walls than in comparable samples that were unshaken. Wheelock and others (2005) found that vortexing scintillation vials returned 100 percent of $\lambda$-cyhalothrin to solution. House and $\mathrm{Ou}$ (1992) rinsed the sample bottle with dichloromethane after the removal of the sample water and were able to reclaim the pyrethroids associated with the surface, although there was not a complete mass balance.

The amount of suspended sediment or dissolved organic carbon (DOC) in a water sample also affects the association of pyrethroids-to-container surfaces. Researchers found that when adding $2 \mathrm{~g}$ of sediment to a water matrix, association to the container for tefluthrin decreased from approximately 60 percent to less than 3 percent after 25 hours (Zhou and others, 1997). Lee and others (2002) found pyrethroid association to $1-\mathrm{L}$ glass bottles to be 30 to 40 percent for deionized water, but this loss decreased to 20 to 30 percent for stormwater runoff containing $25 \mathrm{mg} / \mathrm{L}$ of suspended solids. While pyrethroids sorb to both DOC and suspended sediments, it appears that they prefer suspended sediments to DOC (Liu and others, 2004).

Filtering is another source of loss of pyrethroids during sample handling. House and Ou (1992) tested several filters, including cellulose nitrate, anopore, nuclepore, and glass fiber, and found that the lowest pyrethroid losses occurred with the glass fiber filter (5-20 percent).

Mitigation of the pyrethroid losses has been attempted for analytical purposes. A solvent such as methanol can be added to increase pyrethroid recovery. In one case, 30 percent methanol was added to the water sample prior to solid-phase extraction (SPE) (van der Hoff and others, 1996). The amount of solvent added must be monitored to minimize SPE column breakthrough. This study used C18 SPE cartridges and found that 30 percent was the maximum level before breakthrough. Brouwer and others (1994) were trying to analyze pyrethroids and found their solubility in water could be enhanced by adding Brij-35 (polyoxyethyleneglycol dodecyl ether), a neutral surfactant. Other modifications have been attempted but were not successful at reducing pyrethroid sorption; these include aeration, silylating, using polyethylene glycol (PEG) to coat active sites on the glass surface (Wheelock and others, 2005), and addition of $10 \mathrm{mM}$ carbonate buffer (House and $\mathrm{Ou}$, 1992). 


\section{Sample Holding}

It is important to determine how long samples can be held before pyrethroid association to the container becomes irreversible or degradation begins. In water, the pyrethroids appear to be relatively unstable to degradation when stored in a refrigerator $\left(4^{\circ} \mathrm{C}\right)$. Data from the U.S. Geological Survey (USGS) National Water Quality Laboratory list holding times for $\lambda$-cyhalothrin as 3 days, while the other pyrethroids tested (bifenthrin, cyfluthrin, cypermethrin, and tefluthrin) have holding times of 15 days to greater than 28 days (Sandstrom and others, 2001). One caveat for these holding-time tests is that the method used lists the recovery of these compounds as low and variable (Sandstrom and others, 2001); losses may come from container association rather than from degradation. Another study also found that $\lambda$-cyhalothrin showed significant degradation losses (20 to 30 percent) after only a few days in water (Bennett and others, 2000). Additional studies conducted as part of a pyrethroid method development project by the USGS, California Department of Food and Agriculture, and California Department of Fish and Game showed that the acceptable holding time for water samples is around 4 days, but that with the addition of a keeper solvent (hexane), the holding time can be extended to 28 days (Hladik, 2007).

Pyrethroids in sediment appear to be much more stable to degradation when stored in a freezer $\left(-20^{\circ} \mathrm{C}\right)$. Data from the pyrethroid method development project demonstrated that pyrethroid sediment samples that are frozen can be stable for at least 6 months (Hladik, 2007).

\section{Purpose and Scope}

This report summarizes the findings when various sampling devices were tested for pyrethroid losses and this information lead the development of the validated SOP (appendix A). Following the SOP will help ensure minimal losses of pyrethroids on sampling equipment and container surfaces. The main objective of this project is to test field sampling devices to support the development and validation of a standard operating procedure for the collection of pyrethroids in water and sediment matrices. This report is intended to supplement other documents that describe how to collect water and sediment samples: for example the USGS National Field Manual for the Collection of Water-Quality Data or comparable methods.

\section{Experimental Design and Methodology}

Loss of pyrethroids to sampling containers were conducted using laboratory and natural waters spiked with pyrethroids. Sampling devices tested are those commonly used by researchers who collect water and sediment samples for pyrethroid analysis.

\section{Sample-Collection Design}

Some of the most commonly used sample-collection devices were tested for loss of pyrethroids. As it is hard to find environmental samples that have consistent concentrations of pyrethroids, samples used for this study were laboratoryspiked water and sediment matrices collected from sites that had no known sources of pyrethroid contamination. Deionized water was used only for 1-L grab samples to represent the maximum pyrethroid loss in water matrices, since losses were expected to be somewhat mitigated in the environmental samples due to naturally occurring particulate matter. The rest of the tests were run using natural waters to better simulate field conditions. Water used for the majority of the experiments was collected from the American River near California State University, Sacramento, in 19-L stainless-steel soda kegs, and was subsequently filtered through a $0.7-\mathrm{mm}$ glass-fiber filter into another soda keg and stored at $4^{\circ} \mathrm{C}$. A sufficient volume of American River water could not be collected all at once for testing of all techniques, but changes in water composition were minimal over the duration of the testing (suspended sediment concentrations [SSC] 15-20 mg/L; DOC 1-2 mg/L; pH 6.5-7.5). The American River water had relatively low SSC and DOC, thus minimizing potential sorption competition. In addition, a high-DOC water was mixed with American River water to test the effects of varying the DOC; this water matrix was from Georgia, and was collected in a baked 4-L amber glass bottle; the water was filtered through a $0.7-\mathrm{mm}$ glass fiber filter, and DOC was measured $(40 \mathrm{mg} / \mathrm{L})$. Bed sediment was collected as a depositional grab sample using a stainlesssteel spoon, using methods described by Radtke (2005). Sediment was sieved (stainless mesh) to remove particles larger than $4 \mathrm{~mm}$ in diameter and homogenized with a stainless-steel spoon to ensure consistent composition. Sediment moisture and percent organic carbon were measured (50 and 1 percent, respectively; Hladik and Orlando, 2008). Sediment was stored in a clean, baked, glass container at $-20^{\circ} \mathrm{C}$. All water and sediment matrices were tested for any pyrethroids prior to use in spiking experiments, and none were detected.

\section{Sampling Devices}

\section{Water Matrices}

Devices for sampling waters included grab, composite, integrated, and auto-samplers. Each of these devices was tested according to standard practices (Ward and Harr, 1990; Lane and others, 2003; U.S. Geological Survey, 2006). If appreciable pyrethroid sorption (greater than 10 percent) was found to occur, then the methods were adjusted to try to lessen pyrethroid losses. The adjustments included agitating the samples between transfers, and changing the sample device composition where possible. Table 1 summarizes the devices used to test pyrethroid losses from water to equipment and container surfaces. 
Table 1. Summary of devices tested for pyrethroid losses for water samples.

[Devices were held at 4 degrees Celsius. DCM, dichloromethane; DOC, dissolved organic carbon; i.d., inner diameter; LDPE, low-density polyethylene; L/min, liter per minute; $\mathrm{m}$, meter; $\mathrm{mg} / \mathrm{L}$, milligram per liter; $\mathrm{mL}$, milliliter; $\mathrm{mL} / \mathrm{min}$, milliliter per minute; min, minute; mm, millimeter; ng/L, nanogram per liter]

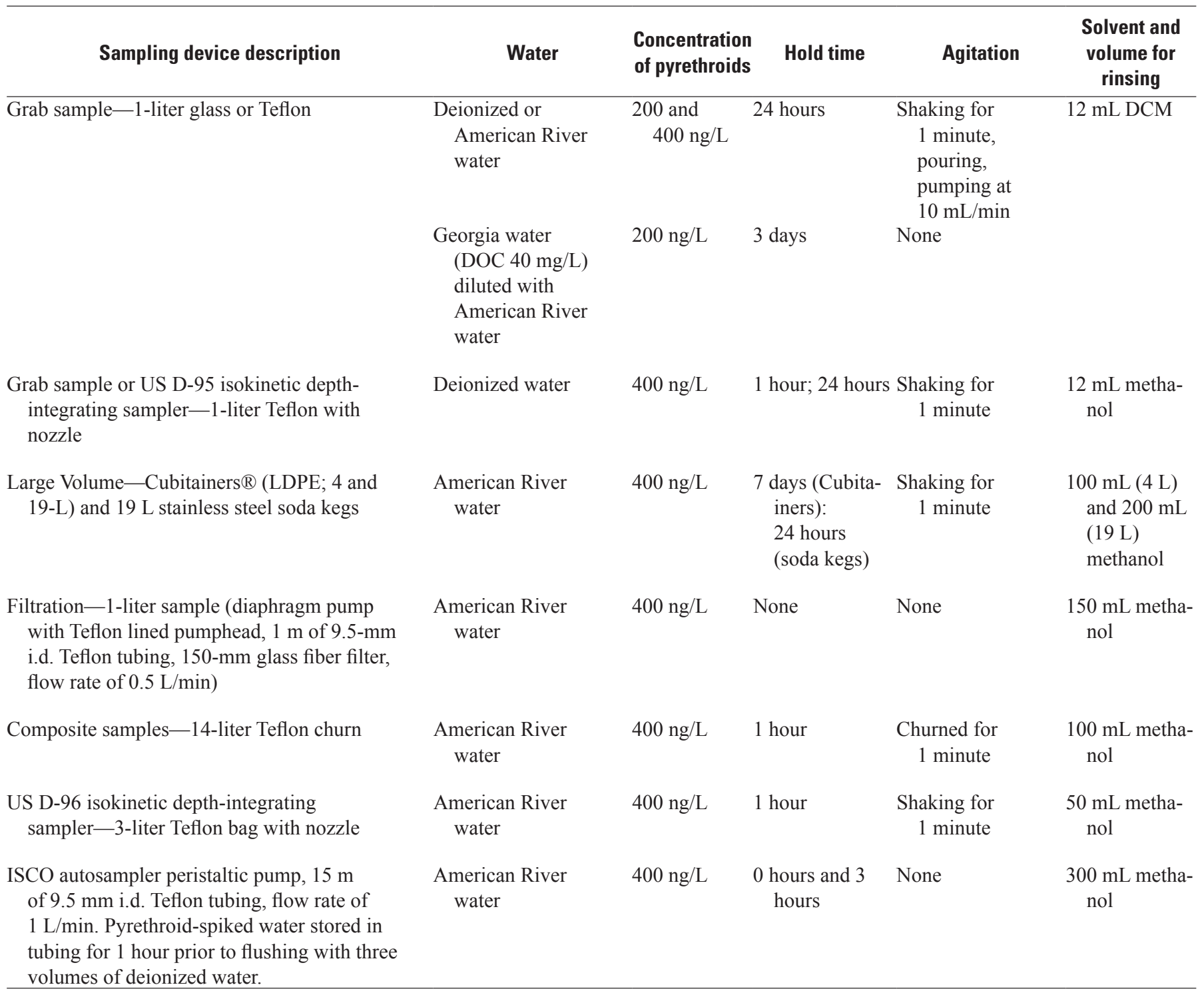

\section{Sediment Matrices}

Sediments sampled for pyrethroid toxicity or chemical analysis are most commonly collected as "grab samples" using a stainless-steel spoon to take the top $2 \mathrm{~cm}$ of depositional sediment. While other sediment-collection methods (for example, Eckman, Ponar, cores; Radtke, 2005) may collect a larger volume of sample than the grab-sample, these generally are not employed for the pyrethroids. Diagnostic sediment samples simulating grab samples were tested by taking sediment $(100 \mathrm{~g})$ from a central California agricultural drain into a $500-\mathrm{mL}$ glass container. This sediment is expected to be representative of most sediments sampled; it is from an agricultural area with 1-percent organic carbon content. The sediment was spiked with pyrethroids at a final concentration of $100 \mathrm{ng} / \mathrm{g}$. The sediment sample was equilibrated at room temperature for 24 hours and then put in the freezer $\left(-20^{\circ} \mathrm{C}\right)$ for an additional 6 days (sediment samples can be stored for up to 6 months in a freezer; Hladik, 2007). After thawing, the sediment was scooped out with a stainless-steel spoon. The spoon and the jar were each rinsed with $10 \mathrm{~mL}$ of dichloromethane. The lid to the jar was not rinsed as the sediment did not come into contact with the Teflon-lined plastic lid. 


\section{Pyrethroid Analysis}

Water and sediment samples were spiked with up to 14 pyrethroids (allethrin, bifenthrin, cyfluthrin, $\lambda$-cyhalothrin, cypermethrin, deltamethrin, esfenvalerate, fenpropathrin, $\tau$-fluvalinate, permethrin, resmethrin, sumithrin, tefluthrin, and tetramethrin) using a methanol carrier solvent. Water samples were spiked to achieve an expected concentration of $400 \mathrm{ng} / \mathrm{L}$, and sediment samples were spiked to achieve an expected concentration of $100 \mathrm{ng} / \mathrm{g}$. Sample containers and sampling apparatus parts were rinsed with methanol or dichloromethane (DCM) after the matrix water was removed, to capture and measure the portion of the pyrethroids that were retained on the surfaces (pyrethroids were not measured in the aqueous solution).

The DCM was effective at removing the pyrethroids associated with the container surface. In previous studies (Hladik, 2007), a mass balance was completed for 1-L water samples in an amber glass bottle; total recoveries ranged from 88 to 95 percent. In separate tests, methanol was found to be as effective as DCM in removing surface-associated pyrethroids. Teflon bottles were rinsed with methanol and then DCM, and no additional levels of pyrethroids were detected in the dichloromethane fraction.

The solvent was blown down under a gentle stream of nitrogen to $0.5 \mathrm{~mL}$, exchanged into ethyl acetate $(0.2 \mathrm{~mL})$, and deuterated internal standards were added. All sample extracts were analyzed by gas chromatography-mass spectrometry (GC/MS). Instrument detection limits were 0.01 to $0.025 \mathrm{ng} /$ $\mathrm{mL}$, which translates to 2 to $5 \mathrm{ng} / \mathrm{L}$ in a water sample (well below the spiking concentrations). Complete details of the GC/MS analysis are described elsewhere (Hladik and others, 2008).

Because only the containers were tested for pyrethroids, the SPE water extraction technique was not used in this study. However, this is a common technique for measuring pyrethroids in water, and the possible losses from this method are explored in this report.

\section{Quality Control}

A number of quality-control checks were implemented to assess whether data quality requirements are being met (table 2). All quality-control checks met or exceeded California Surface Water Ambient Monitoring Program (SWAMP) requirements (California State Water Resources Control Board, 2002). Many samples collected in California are required to meet SWAMP criteria; therefore these standards are used. Because this study involved only laboratory-spiked water- and sediment matrices to test sampling devices, no field blanks or field replicates were needed.

\section{Results}

The results are presented according to matrix (water or sediment) and sample device tested. Quality control for each device is presented within each section.

\section{Sample Devices for Water Matrices}

Results are presented for two types of 1-L containers (glass and Teflon) and three types of large-volume containers (4-L and 19-L LDPE Cubitainers ${ }^{\circledR}$ and 19-L stainless-steel soda kegs).

\section{One-Liter Containers}

Glass

One-liter glass containers were tested using deionized water and natural water matrices. For tests using deionized water, the deionized water was removed from the glass bottles in one of three ways: by a pump at $10 \mathrm{~mL} / \mathrm{min}$ to simulate SPE; poured out of the bottle; or, shaken vigorously for 1 minute before the water was poured out of the bottle. Pumping the water at $10 \mathrm{~mL} / \mathrm{min}$ to simulate SPE conditions gave the most sorption (fig. 1); in deionized water, the surface-association was near 30 percent for most compounds (fig. 1). Pouring out the water or shaking the bottle vigorously for 1 minute before pouring out the water reduced losses caused by association to the container walls to below 5 percent (fig. I). Testing two different concentrations of aqueous pyrethroids (200 and $400 \mathrm{ng} / \mathrm{L}$ ) and removing the water by pumping showed no significant difference in the amount of loss at the two different concentrations (fig. 2).

The amount of loss to glass containers also depended on the composition of the water. To test how pyrethroid sorption to dissolved compounds in a natural water can affect the pyrethroid association to the container walls, samples that had varying concentrations of DOC $(1,4$, and $8 \mathrm{mg} / \mathrm{L}$ that were made as a blend of American River water and a 40-mg/LDOC water from Georgia) were spiked with pyrethroids. The water for each bottle was removed by pumping at $10 \mathrm{~mL} / \mathrm{min}$. The results showed that the higher the DOC concentration the lower the loss to the bottle walls (fig. 3). The pyrethroids prefer to associate with the dissolved compounds rather than the container walls (in this case only glass was tested). 
Table 2. Comparison of the project quality-assurance/quality-control ( $\mathrm{QA} / \mathrm{CC}$ ) plan with the Surface Water Ambient Monitoring Program (SWAMP) quality-control requirements for organic constituents (pesticides) in water and sediment.

[SWAMP QC plan information from California State Water Resources Control Board, 2002. Acceptance criteria meets both SWAMP and project QA/QC plan criteria. GC, gas chromatography ; GC/MS, gas chromatography/mass spectrometry; L, liter; MDL, method detection limit; QA/QC, quality assurance/quality control; $\mathrm{RPD}$, relative percent difference; SRM, standard referece material; <, less than; >, greater than]

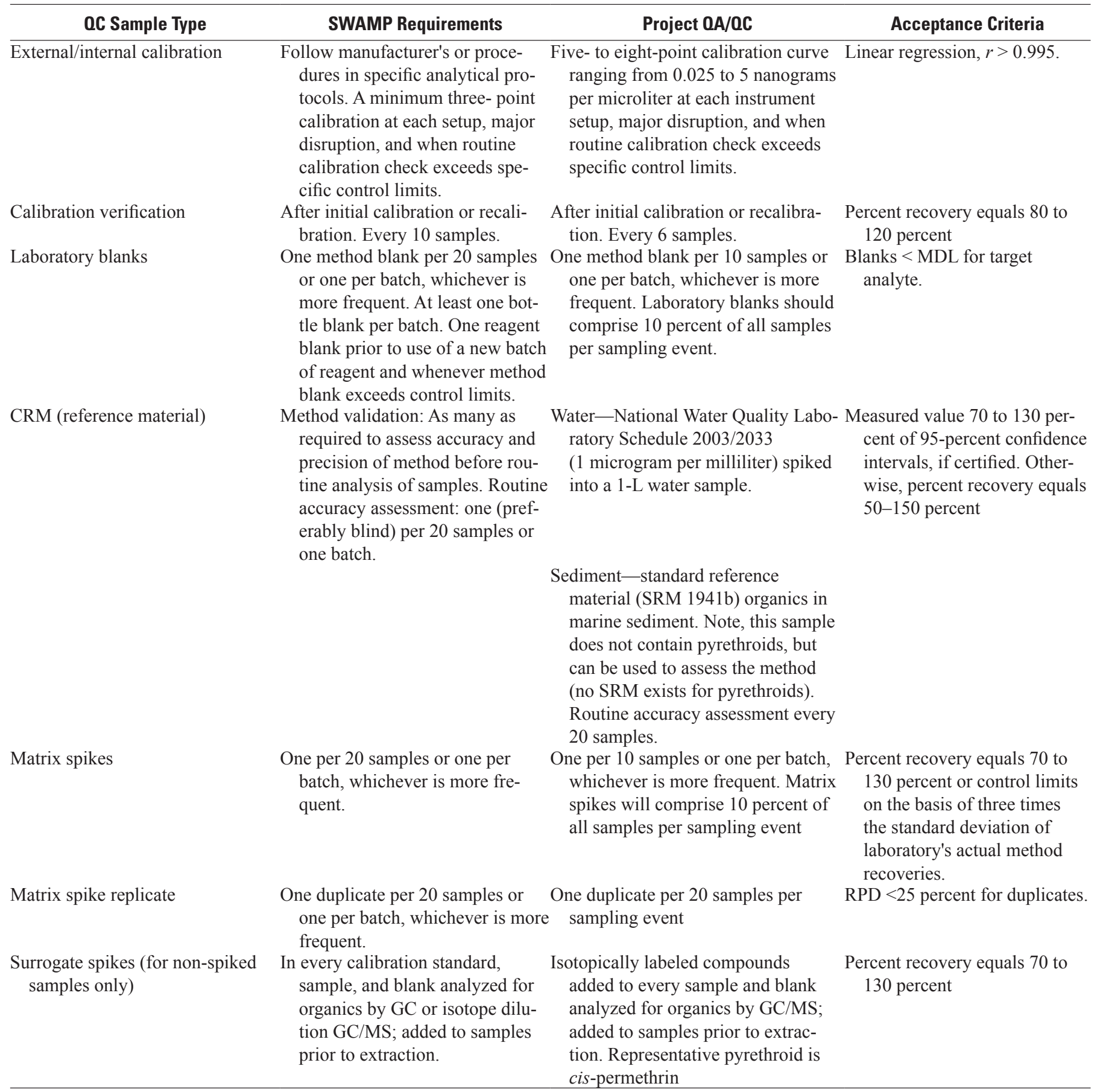




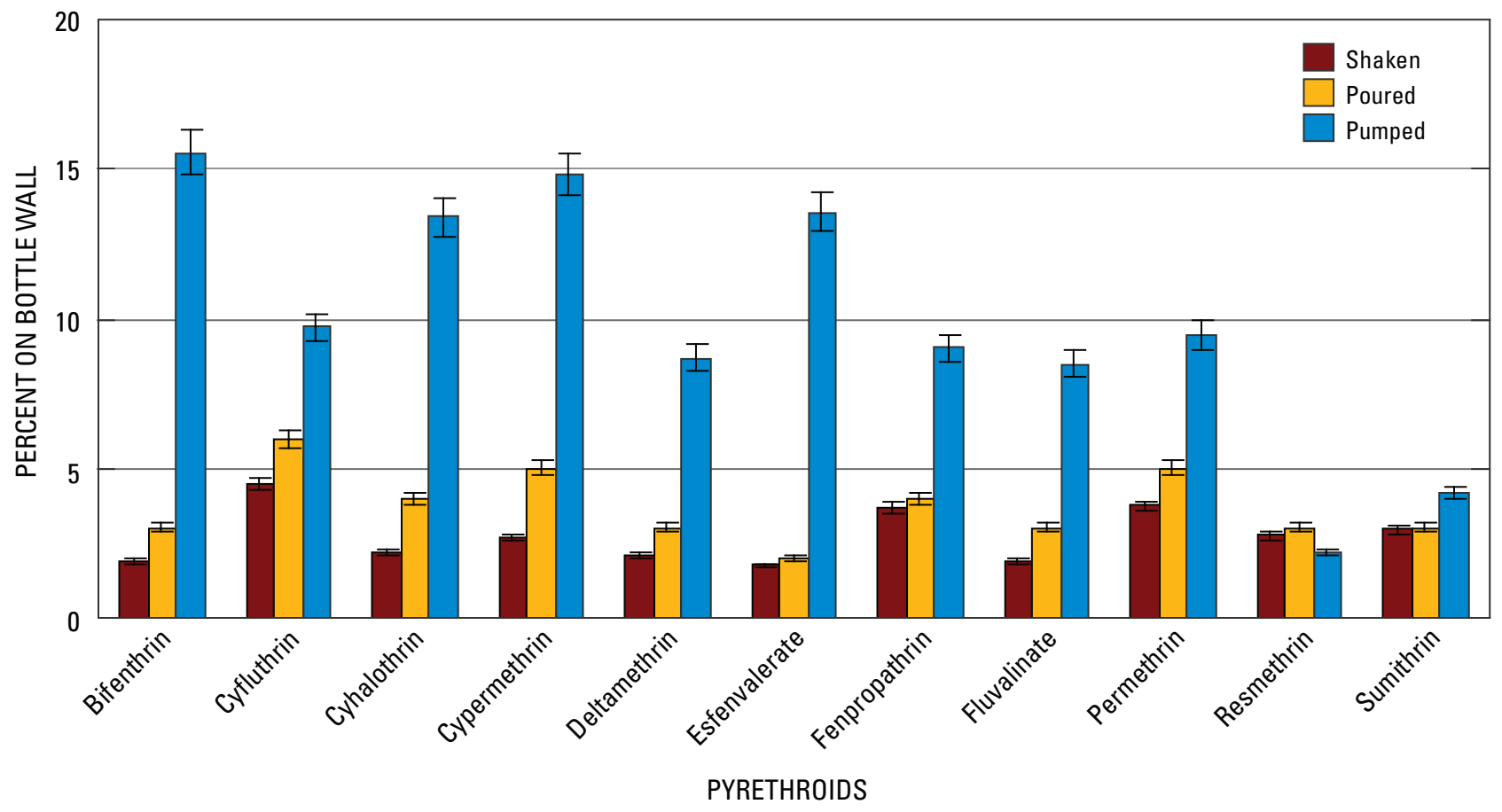

Figure 1. Fraction of pyrethroids associated with 1-liter glass bottle walls. Pyrethroids were spiked at 400 nanograms per liter into deionized water. Spiked bottles were allowed to sit for 24 hours prior to having the water removed by pumping at 10 milliliters per minute, pouring the water out of the bottle or shaking the bottle for 1 minute and then pouring the water out of the bottle.

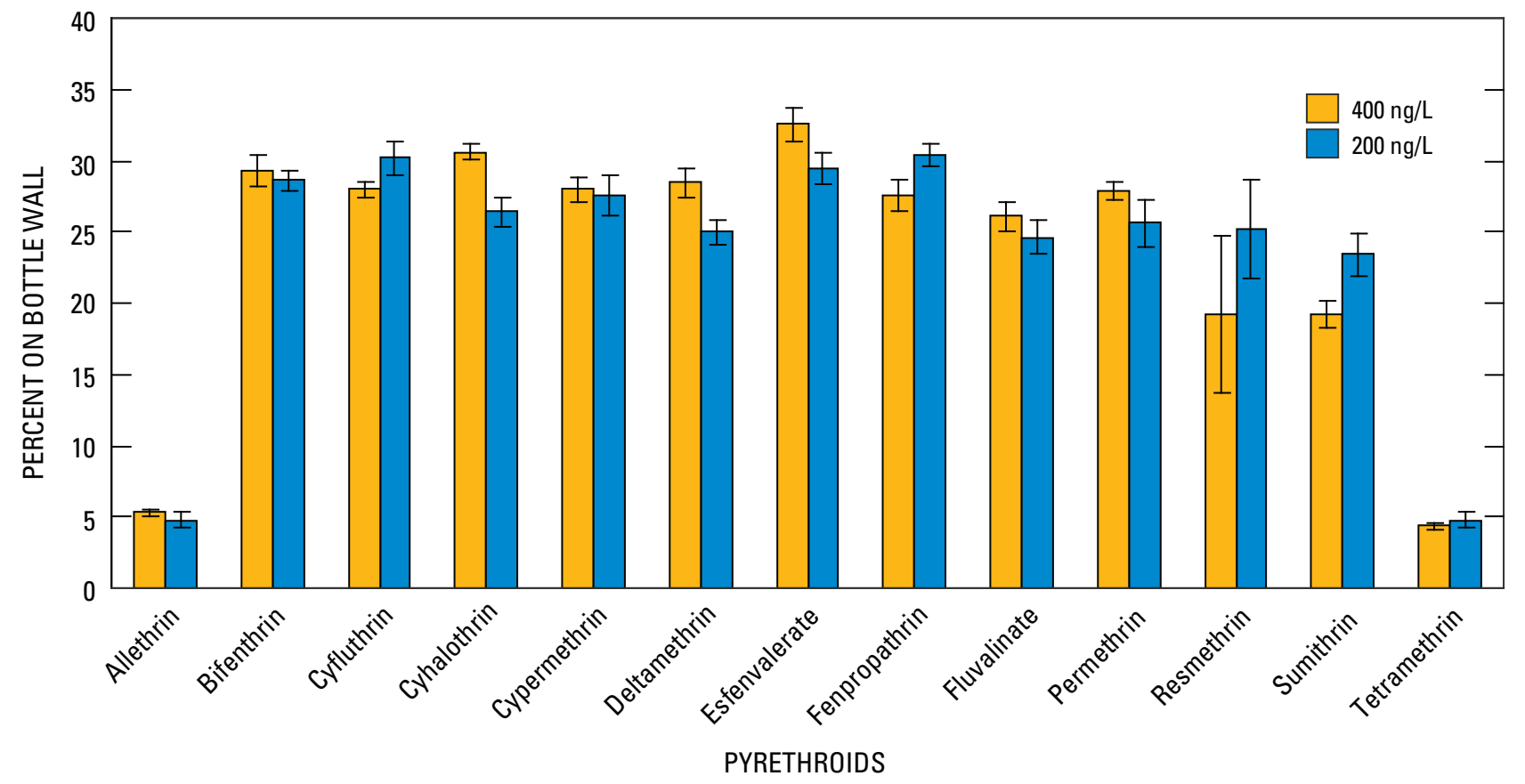

Figure 2. Fraction of pyrethroids associated with 1-liter glass bottles at two different concentrations. Pyrethroids were spiked at 400 or 200 nanograms per liter ( $\mathrm{ng} / \mathrm{L}$ ) into deionized water. Spiked bottles were allowed to sit for 24 hours prior to having the water removed by pumping at 10 milliliters per minute. 


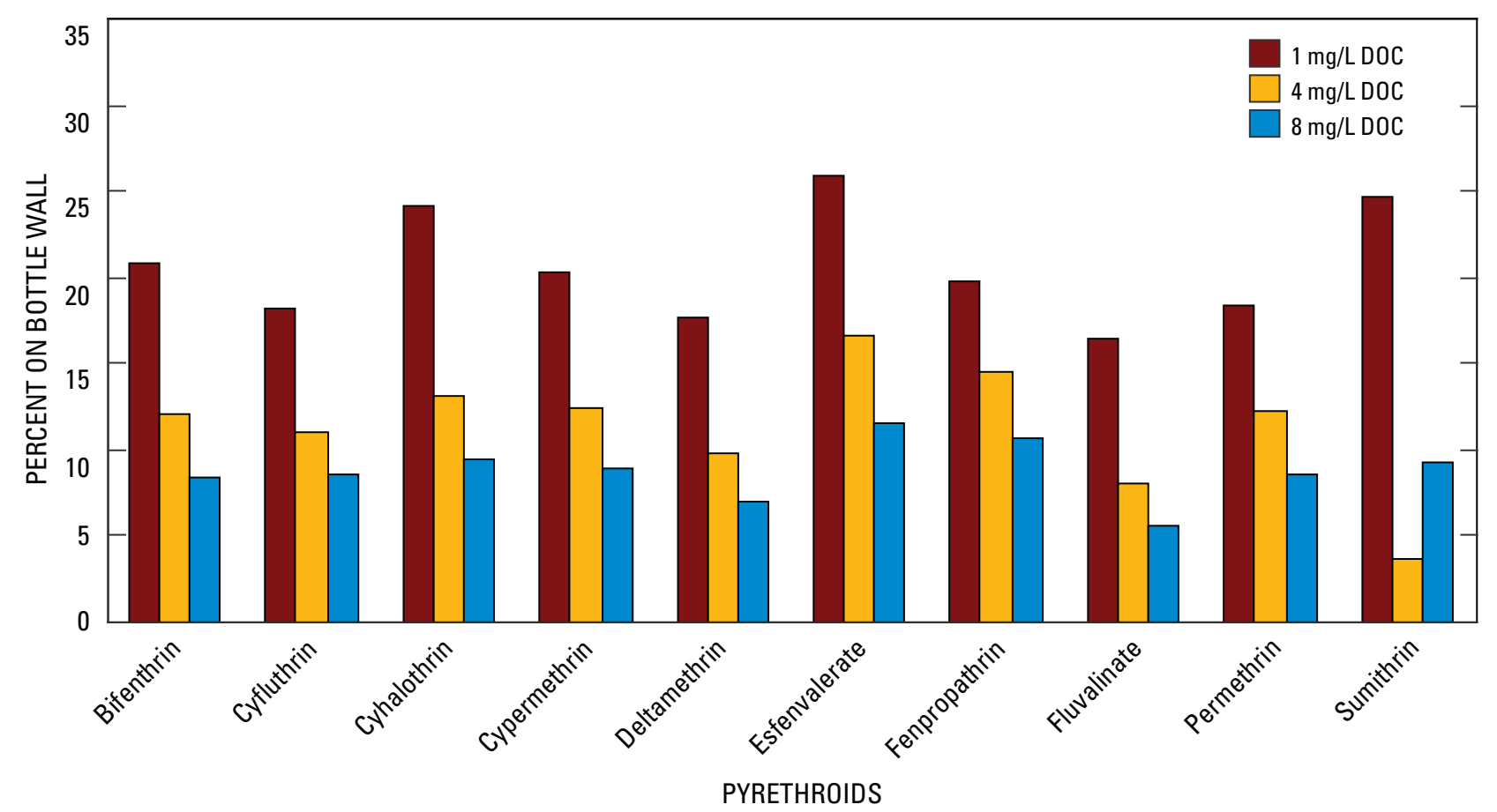

Figure 3. Fraction of pyrethroids associated with 1-liter glass bottles with varying DOC. Pyrethroids were spiked at 400 nanograms per liter into a blend of filtered natural waters. Spiked bottles were allowed to sit for 3 days prior to having the water removed by pumping at 10 milliliters per minute.

\section{Teflon}

Teflon bottles can be used to obtain a grab sample or as part of a US D-95 isokinetic depth-integrating sampler. The Teflon bottle is connected to a Teflon nozzle and encased in the sampler housing. The water sample only contacts the Teflon bottle and nozzle, so these were tested for pyrethroid losses. The losses caused by association to the Teflon bottle are presented below. There were no losses to the Teflon nozzle (water was poured through but did not come into contact with the nozzle for extended periods of time).

Teflon bottles had greater losses of pyrethroids than did glass containers under similar conditions (fig. 4). The glass bottles had pyrethroid losses in the range of 20 to 30 percent while losses for the Teflon bottles were 30 to 40 percent (for most compounds). When the Teflon bottles were shaken for 1 minute before the contents were poured out, the amount of loss decreased to 10 to 20 percent (fig. 5). Shaking did not decrease the pyrethroid loss for the Teflon bottles as much as it did for the glass bottles. A test of shaking for longer amounts of time also did not decrease the pyrethroid loss to the Teflon bottle, indicating the some of the pyrethroids might be associating more strongly to the Teflon bottle.

Another set of Teflon bottles was spiked and allowed to sit for only 1 hour (more representative of an integrated field sample) rather than for 24 hours. The pyrethroid losses were less than 10 percent for all compounds if the bottles were shaken before the water was poured out (fig. 5). These data suggest that glass bottles should be used whenever possible, and that if Teflon must be used (such as for an integrated sample), then it is optimal to transfer the sample to a glass bottle as soon as possible to minimize losses of pyrethroids.

\section{Large-Volume Containers}

\section{Low-density polyethylene 4- and 19-liter Cubitainers ${ }^{\circledR}$}

Association of pyrethroids to the walls of the LDPE Cubitainers ${ }^{\circledR}$ was low. LDPE containers were tested because they commonly are used by toxicologists working with pyrethroid solutions. The 4-L containers had zero to 7 percent of pyrethroids remaining on the walls after the water was removed, whereas the 19-L containers had zero to 4 percent remaining on the walls (table 3 ). The loss was lower for the larger container because the volume-to-contact-area ratio of the water to the container surface is greater; 4.5 and $2.6 \mathrm{~mL} /$ $\mathrm{cm}^{2}$ for the 19- and 4-L containers, respectively. Water samples were held for 1 week to simulate sample collection procedures used by other researchers for toxicity tests. Pyrethroid degradation may have occurred, as shown by other researchers (Sandstrom and others, 2001), and it is not recommended that water samples be kept this long before analysis. 


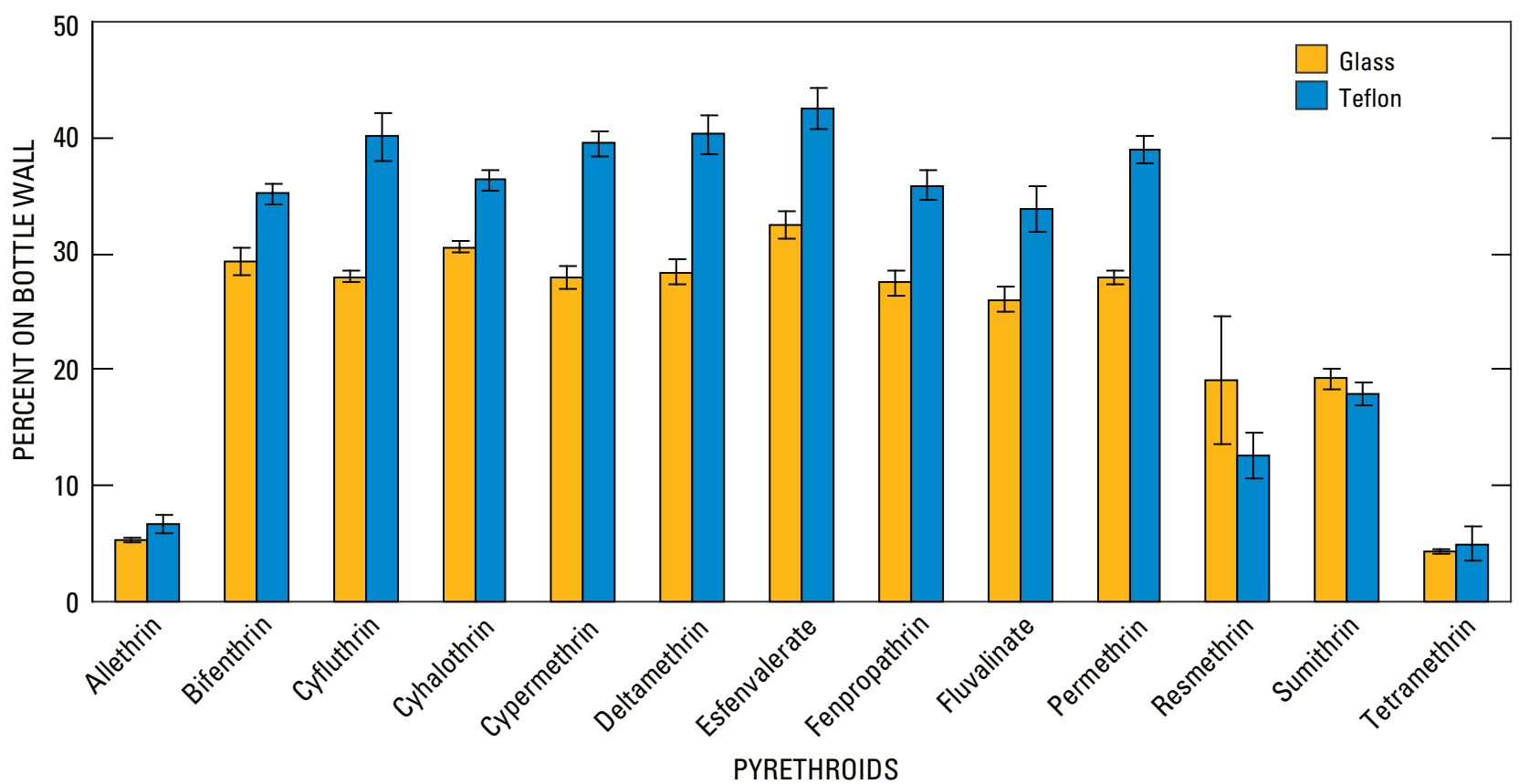

Figure 4. Fraction of pyrethroids associated with 1 -liter glass and Teflon bottles. Pyrethroids were spiked at 400 nanograms per liter into deionized water. Spiked bottles were allowed to sit for 24 hours prior to having the water removed by pumping at 10 milliliters per minute.

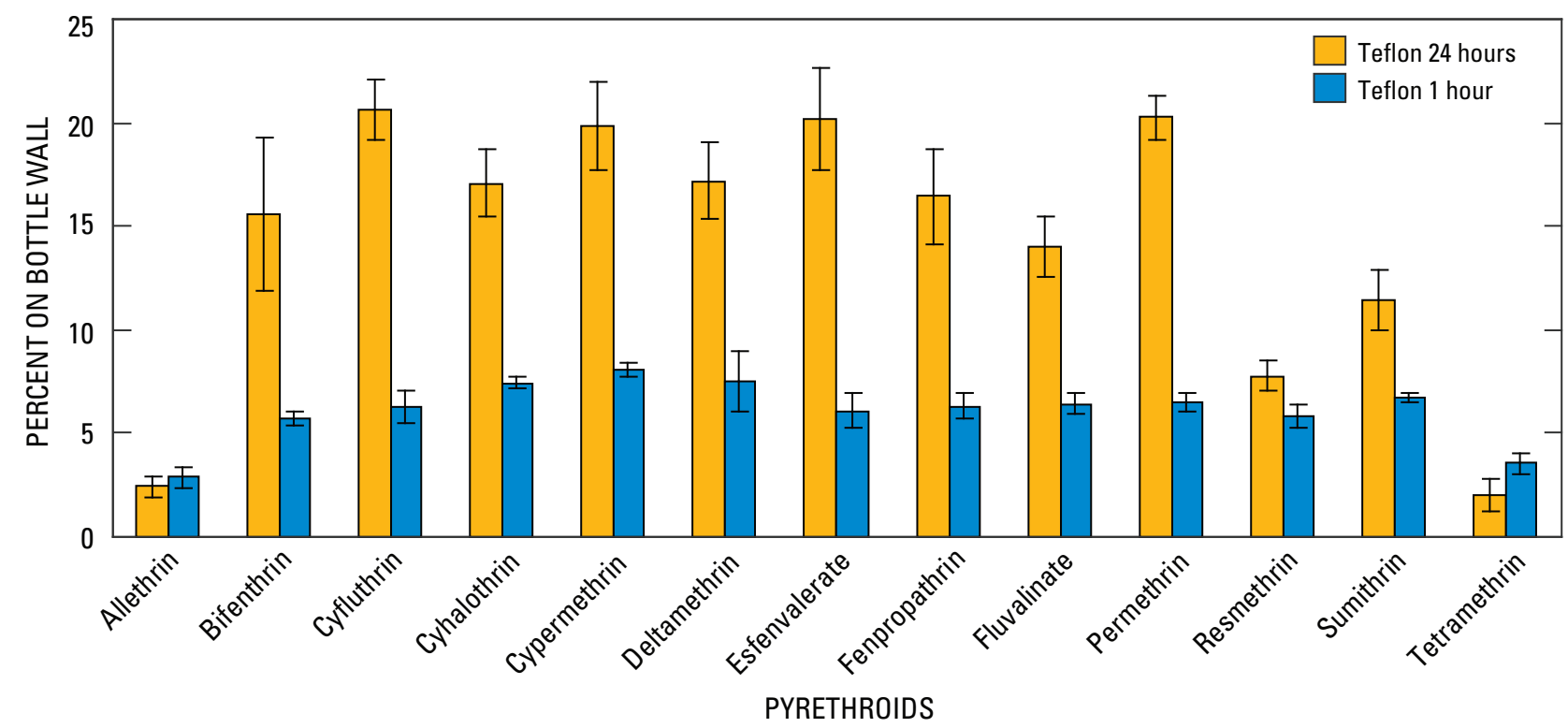

Figure 5. Fraction of pyrethroids associated with 1-liter Teflon bottles. Pyrethroids were spiked at 400 nanograms per liter into a natural water (dissolved organic carbon $=2$ milligrams per liter). Spiked bottles were allowed to sit for 1or 24 hours prior to having the water removed by shaking for 1 minute and then pouring the water out of the bottle. 
Table 3. Loss of pyrethroids to 4-liter and 19-liter Cubitainers ${ }^{\circledR}$, and to 19-liter stainless-steel soda kegs.

[Pyrethroid concentration in the water was 400 nanograms per liter; samples sat for 1 week (Cubitainers) or 24 hours (soda kegs) before being shaken for 1 minute and the water removed; $\mathrm{n}=3$; L, liter. Values are given in percent. Value in parentheses is the standard deviation, in percent]

\begin{tabular}{lccc}
\hline Compound & $\begin{array}{c}\text { 4-liter Cubitainer } \\
\text { percent loss }\end{array}$ & $\begin{array}{c}\text { 19-liter Cubitainer® } \\
\text { percent loss }\end{array}$ & $\begin{array}{c}\text { 19-liter stainless-steel soda keg } \\
\text { percent loss }\end{array}$ \\
\hline Allethrin & $0(0)$ & $0(0)$ & $1(0)$ \\
Bifenthrin & $6(1)$ & $3(0)$ & $4(0)$ \\
Cyfluthrin & $7(1)$ & $3(0)$ & $3(1)$ \\
$\lambda$-Cyhalothrin & $5(1)$ & $3(1)$ & $2(0)$ \\
Cypermethrin & $6(1)$ & $3(0)$ & $2(1)$ \\
Deltamethrin & $4(1)$ & $3(1)$ & $3(0)$ \\
Esfenvalerate & $6(1)$ & $4(1)$ & $3(0)$ \\
Fenpropathrin & $5(1)$ & $3(1)$ & $2(0)$ \\
$\tau$-Fluvalinate & $5(1)$ & $3(0)$ & $3(1)$ \\
Permethrin & $6(1)$ & $3(0)$ & $4(0)$ \\
Resmethrin & $5(0)$ & $3(0)$ & $1(0)$ \\
Sumithrin & $4(1)$ & $3(0)$ & $4(0)$ \\
Tetramethrin & $0(0)$ & $0(0)$ & $2(1)$ \\
\hline
\end{tabular}

\section{Nineteen-Liter Stainless-Steel Soda Kegs}

Nineteen-L soda kegs were filled with water from the American River and spiked with pyrethroids. The samples were allowed to sit for 24 hours. The water was then agitated for 1 minute and poured out of the soda keg. Loss of pyrethroids to the inner stainless-steel surfaces of the soda kegs was minimal (table 3); the amount of pyrethroids that remained associated to the walls was less than 4 percent for all compounds.

\section{Collection and Processing Equipment for Water Matrices}

Collection and sample-processing equipment tested for this study included filtration apparatus, Teflon churns used for compositing samples, the US D-96 Isokenetic Depth-Integrating Sampler, and an ISCO autosampler (Teledyne Isco, Inc., Lincoln, Nebraska).

\section{Filtration Apparatus}

About 10 percent of the pyrethroids spiked into the 1-L water samples and then run through the pump $(500 \mathrm{~mL} / \mathrm{min})$ for filtration were retained in the pump filter (see table 1 for more details) and housing (fig. 6); however, not all of this mass is from pyrethroids associating to the surfaces of the apparatus. The pump housing holds about 50 to $75 \mathrm{~mL}$ of water that we infer would account for 5 to 7 percent of the loss; the loss to the housing is a loss that would be encountered in any filtration, and is not unique to the pyrethroids. The pump-housing loss does not affect the concentration in the water, just the total volume of water after filtration. Additional deionized water was not filtered through the pump after the sample because some of the pyrethroids associating to the surfaces of the apparatus might have become re-suspended. Taking into account the amount of water left in the housing, the loss of pyrethroids to the surfaces themselves was inferred to be minimal and no further tests were undertaken. An additional indication that the mass left in the pump housing is from residual water (and not surface-associated pyrethroids) is the amount of allethrin and tetramethrin measured. Allethrin and tetramethrin vary in their ring structure (they do not contain benzene rings) from the other pyrethroids and they do not associate to containers to the same degree as the other pyrethroids (figs. 2 and 4), indicating these compounds remain in the aqueous phase.

\section{Teflon Churn}

The Teflon churn consists of a thick-walled, cylindrical vessel and agitator and a "push-pull" type spigot that is supplied to draw off sub-samples from the splitter. The churn used for this study has a volume of $14 \mathrm{~L}$. For a 3-L volume of samples water in the, pyrethroid losses ranged from 8 to 16 percent (fig. 7). As with the pump (tested previously), there were about $50 \mathrm{~mL}$ of water that could not be removed from the churn prior to rinsing, accounting for approximately 2 percent of the mass of pyrethroids that was lost. The $3 \mathrm{~L}$ of water in the churn represents the worst-case scenario, as this is the smallest amount of water that would be placed in the churn, having the smallest volume-to-contact-area ratio. To further test losses to the churn, $8 \mathrm{~L}$ of water was tested. Pyrethroid losses were less than 7 percent (fig. 7), because of the increased volume-to-contact-area ratio. To minimize losses of pyrethroids to the churn, a larger volume of water $(>3 \mathrm{~L})$, or a smaller churn, should be used. 


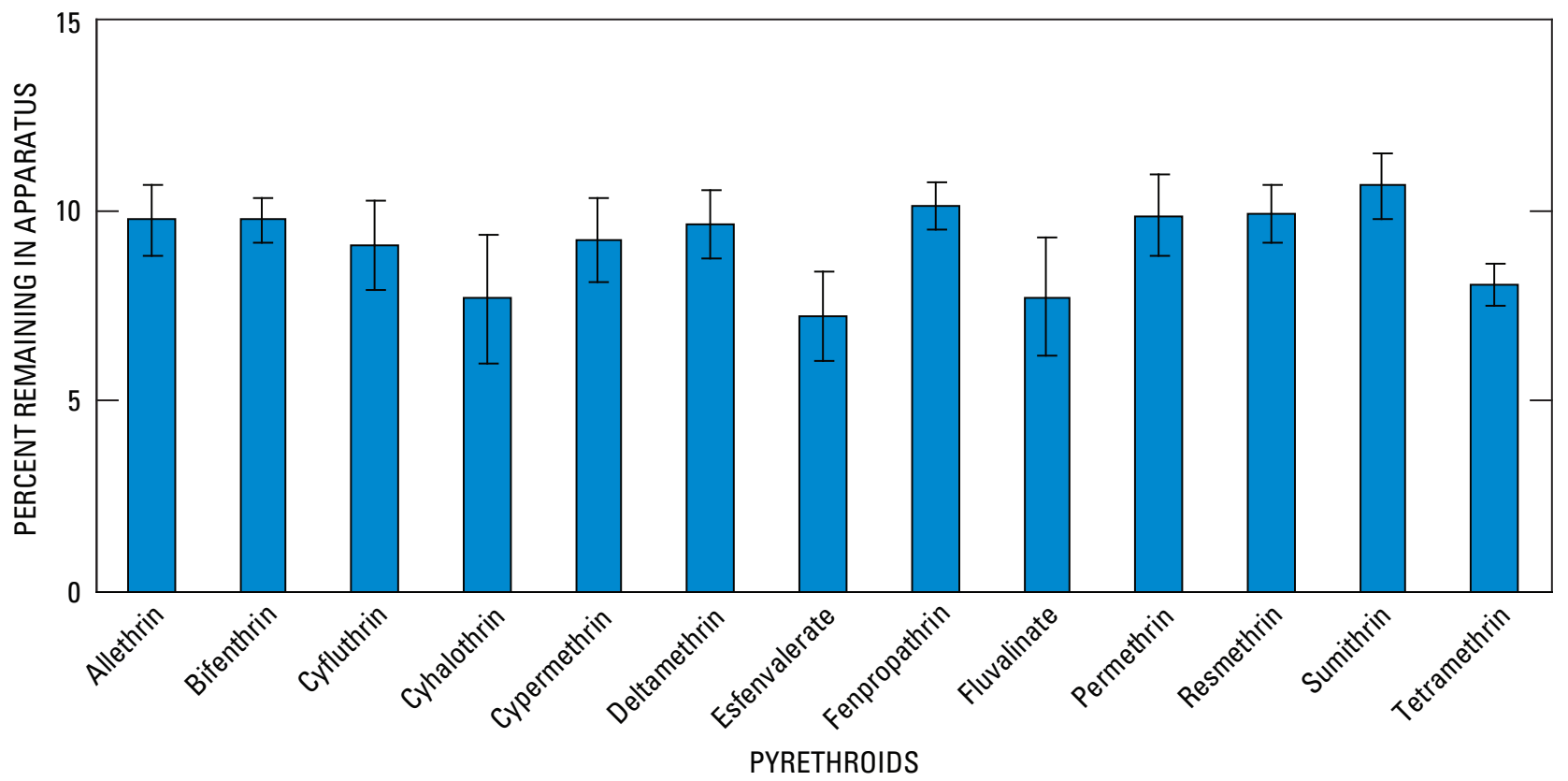

Figure 6. Fraction of pyrethroids left in the filtration pump. Pyrethroids were spiked at 400 nanograms per liter into a natural water (dissolved organic carbon $=2$ milligrams per liter) in 1-liter Teflon bottles. Water from the pyrethroid spiked bottles were run through the pump at 500 milliliters per minute.

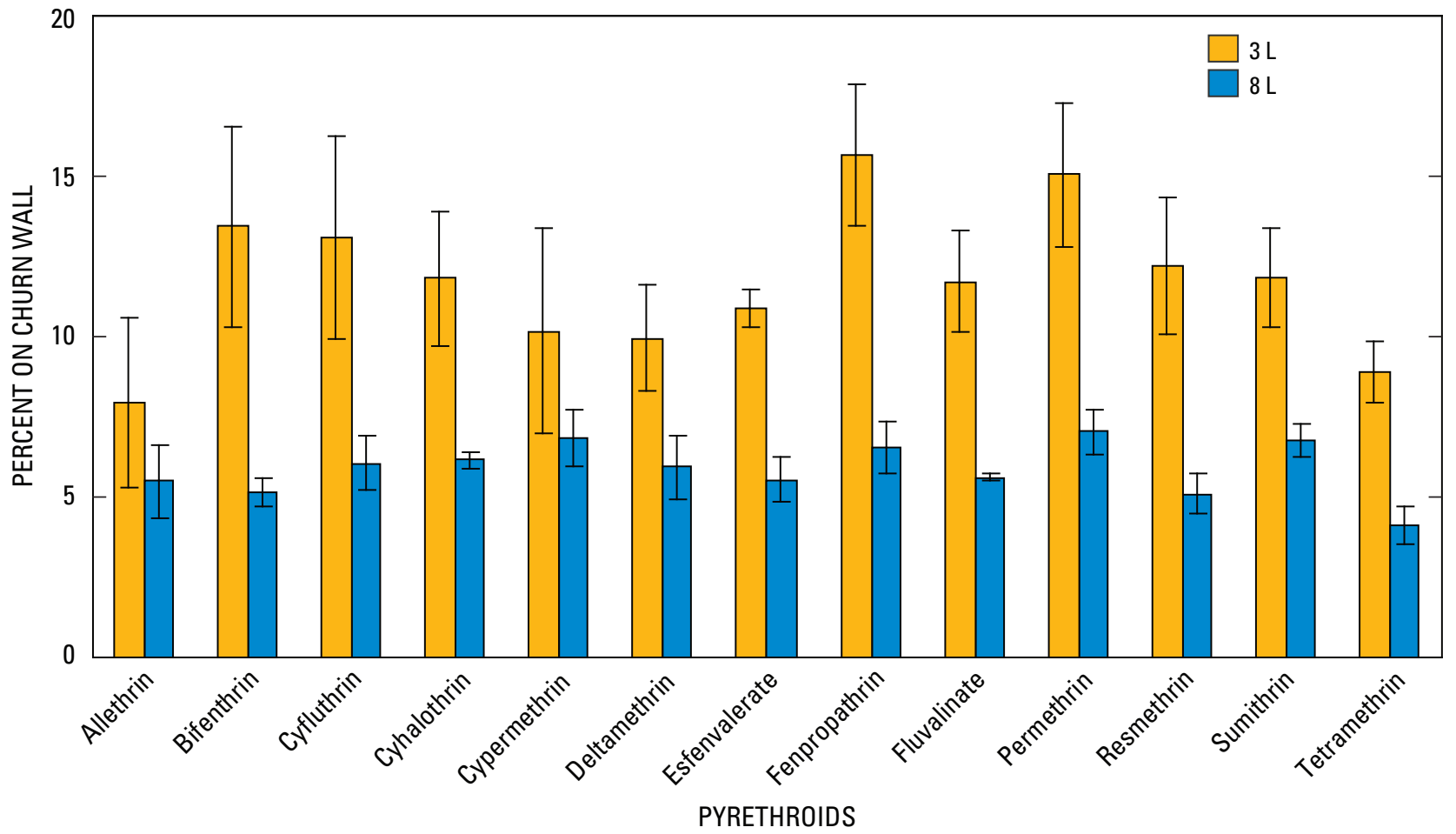

Figure 7. Fraction of pyrethroids associated with the churn walls. Pyrethroids were spiked at 400 nanograms per liter into 3 or 8 liters of a natural water (dissolved organic carbon = 2 milligrams per liter) in a 14-liter Teflon churn. The pyrethroid spiked water was allowed to sit in the churn for 1 hour prior to having the water removed. 


\section{US D-96 Isokenetic Depth-Integrating Sampler}

The US D-96 sampler holds a 3-L Teflon bag that is connected to a Teflon nozzle and encased in the sampler housing. The water sample only contacts the Teflon bag and nozzle, so these were tested for pyrethroid losses. The losses to the Teflon bag are presented below. There were no losses to the Teflon nozzle (water was poured through but did not come into contact with the nozzle for extended periods of time).

Pyrethroid losses to the 3-L Teflon bag used with the D-96 was between approximately 2 and 10 percent (table 4); as seen with other bottles, Teflon is not the best material to minimize pyrethroid association to the container wall. Shaking the bags did not disassociate the pyrethroids from the inner surfaces of the bag (as observed by no measurable change in pyrethroid losses).

\section{ISCO Autosampler}

The autosampler is set to pump water through tubing into sample containers at pre-determined time points. The water that contacts tubing goes up to and through the autosampler before entering the end sample container. Once each sample container is full, the autosampler can be purged with sample water to an outlet before filling the next sample container.

Sorption to the autosampler was tested under two conditions: the first scenario had pyrethroid-spiked water pumped through the system, the system was drained (to simulate sample collection), and purged with deionized water and then solvent-rinsed; the second scenario differed from the first in that the pyrethroid-spiked water was allowed to sit for 3 hours

Table 4. Losses of pyrethroids to 3-liter Teflon bags.

[Pyrethroid concentration in the water was 400 nanograms per liter; samples sat for 1 hour before being shaken for 1 minute and the water removed; $\mathrm{n}=3$. Values are given in percent]

\begin{tabular}{lcc}
\hline \multicolumn{1}{c}{ Compound } & $\begin{array}{c}\text { Percent } \\
\text { loss }\end{array}$ & $\begin{array}{c}\text { Standard } \\
\text { deviation }\end{array}$ \\
\hline Allethrin & 3 & 1 \\
Bifenthrin & 8 & 1 \\
Cyfluthrin & 10 & 2 \\
$\lambda$-Cyhalothrin & 9 & 2 \\
Cypermethrin & 9 & 1 \\
Deltamethrin & 9 & 1 \\
Esfenvalerate & 9 & 1 \\
Fenpropathrin & 9 & 2 \\
$\tau$-Fluvalinate & 10 & 2 \\
Permethrin & 4 & 1 \\
Resmethrin & 7 & 3 \\
Sumithrin & 8 & 2 \\
Tetramethrin & 2 & 0 \\
\hline
\end{tabular}

in the autosampler prior to purging with deionized water. The purpose of the second test was to simulate the sampling of matrix water having a high concentration of pyrethroids, and to determine if this would contaminate subsequent samples. The glass sample containers that typically are used in the ISCO autosampler were not tested for pyrethroid losses, these are the final sample containers and the pyrethroids associating to the containers can be resuspended easily and losses should be no more than 5 percent (similar to 1-L glass bottles).

When the autosampler was rinsed with organic solvent to remove any associated pyrethroids, the extracts had no detectable losses of pyrethroids in either of the cases tested. The lack of associated pyrethroids in the rinsate indicates that purging the autosampler with deionized water is enough to resuspend any pyrethroids that associated to the apparatus while the water was stagnant (even if the water contained high levels of pyrethroids).

\section{Sample Containers for Sediment Matrices}

Pyrethroid losses from sediment samples to the inside surfaces of glass jars used for sample collection were less than 2 percent (table 5), indicating that sediment-bound pyrethroids are less likely to associate to glass containers than to aqueous pyrethroids. Negligible amounts ( 0 to 0.1 percent) of pyrethroids were found on the spoon used to transfer the sediments. These tests cover the most commonly used method for the collection of pyrethroids associated with sediments, although other methods are available (see Sampling Devices section of this report.)

Table 5. Losses of pyrethroids from sediment to 500-milliliter glass jars.

[Pyrethroid concentration in the sediment was 100 nanograms per gram; sediment was removed with a stainless-steel spoon; $\mathrm{n}=3$. Values given in percent]

\begin{tabular}{lcc}
\hline \multicolumn{1}{c}{ Compound } & $\begin{array}{c}\text { Percent } \\
\text { loss }\end{array}$ & $\begin{array}{c}\text { Standard } \\
\text { deviation }\end{array}$ \\
\hline Allethrin & 1 & 0 \\
Bifenthrin & 1 & 0 \\
Cyfluthrin & 1 & 0 \\
$\lambda$-Cyhalothrin & 1 & 0 \\
Cypermethrin & 1 & 0 \\
Deltamethrin & 1 & 0 \\
Esfenvalerate & 1 & 0 \\
Fenpropathrin & 1 & 0 \\
$\tau$-Fluvalinate & 1 & 0 \\
Permethrin & 2 & 0 \\
Resmethrin & 1 & 0 \\
Sumithrin & 1 & 0 \\
Tetramethrin & 0 & 0 \\
\hline
\end{tabular}




\section{Summary}

Techniques and information to minimize pyrethroid association to the surfaces of sampling equipment and containers are listed below:

- Container composition affects the extent of aqueous pyrethroid loss; pyrethroids associate less to glass containers than to plastic (HDPE or LDPE), and Teflon has the greatest pyrethroid loss caused by association to the container surface.

- Containers should be agitated vigorously for at least 1 minute immediately before transfer to another sample container.

- Maximize the volume-to-contact-area ratio.

- When using a filtration apparatus or autosampler, pump speeds should be at $500 \mathrm{~mL} / \mathrm{min}$ when pumping aqueous pyrethroids.

- Composition of the water matrix affects the extent of pyrethroid association. Higher amounts of DOC or suspended sediments lessen the amount of pyrethroids associated to the container surfaces.

- Appreciable losses of pyrethroids were not found for sediment samples collected in glass containers.

- When possible, water samples should be analyzed within 3 days of collection. Sediment samples can be frozen for up to 6 months (prior to extraction).

\section{References Cited}

Bennett, E.R., Moore, M.T., Cooper C.M., and Smith, S., 2000, Method for the simultaneous extraction and analysis of two current use pesticides, atrazine and lambda-cyhalothrin, in sediment and aquatic plants: Bulletin of Environmental Contamination and Toxicology, v. 64, p. 825-833.

Brouwer, E.R., Struys, E.A., Vreuls, J.J., and Brinkman, U.A.T., 1994, Automated-determination of pyrethroid insecticides in surface-water by column liquid-chromatography with diode-array UV detection, using online micellemediated sample preparation: Fresenius Journal of Analytical Chemistry, v. 350, p. 487-495.

California Department of Pesticide Regulation, 2005, Pesticide use data for 2005 [digital data]: Sacramento, California, Department of Pesticide Regulation.

California State Water Resources Control Board, 2002, Quality assurance management plan for the State of California's Surface Water Ambient Monitoring Program: "SWAMP", 144 p. http://www.swrcb.ca.gov/swamp/docs/swamp_qapp. $p d f$.
Hladik, M.L., 2007, Methods development for the analysis of pyrethroid pesticides in environmental samples: Final report for CALFED Recipient Agreement No. ERP-02-P42, 98 p.

Hladik, M.L., and Orlando, J.L., 2008, Level 1 water-quality inventory of baseline levels of pesticides in urban creeksGolden Gate National Recreation Area and the Presidio of San Francisco, California: U.S. Geological Survey Data Series 338, 14 p.

Hladik, M.L., Smalling, K.L., and Kuivila, K.M., 2008, A multi-residue method for the analysis of pesticides and pesticide degradates in water using HLB solid-phase extraction and gas chromatography-ion trap mass spectrometry: Bulletin of Environmental Contamination and Toxicology, v, 80, p. 139-144.

House, W.A., and Ou, Z., 1992, Determination of pesticides on suspended solids and sediments: Investigation on the handling and separation: Chemosphere, v. 24, p. 819-832.

Lane, S.L., Flanagan, Sarah, and Wilde, F.D., March 2003, Selection of equipment for water sampling (ver. 2.0): U.S. Geological Survey Techniques of Water-Resources Investigations, book 9, chap. A2, accessed October 7, 1998, at http://pubs.water.usgs.gov/twri9A2/

Lee, S., Gan, J.Y., and Kabashima, J., 2002, Recovery of synthetic pyrethroids in water samples during storage and extraction: Journal of Agricultural and Food Chemistry, v. 50, p. 7194-7198.

Liu, W.P., Gan, J.J., Lee, S., and Kabashima, J.N., 2004, Phase distribution of synthetic pyrethroids in runoff and stream water: Environmental Toxicology and Chemistry, v. 23, p. $7-11$.

Radtke, D.B., revised June 2005, Bottom-material samples: U.S. Geological Survey Techniques of Water-Resources Investigations, book 9, chapter A8: Bottom sample materials. Available at http://pubs.water.usgs.gov/twri9A.

Sandstrom, M.W., Stroppel, M.E., Foreman, W.T., and Schroeder, M.P., 2001, Methods of analysis by the U.S. Geological Survey National Water Quality Laboratory-Determination of Moderate-Use Pesticides and Selected Degradates in Water by C-18 Solid-Phase Extraction and Gas Chromatography/Mass Spectrometry: U.S. Geological Survey WaterResources Investigation Report 01-4098, 70 p.

Sharom, M.S. and Solomon, K.R., 1981, Adsorption and desorption of permethrin and other pesticides on glass and plastic materials used in bioassay procedures: Canadian Journal of Fisheries and Aquatic Sciences, v. 38, p. 199204.

TDC Environmental, 2005, Pesticides in urban surface water: Urban pesticides use trends annual report 2005, 29 p. 
TDC Environmental, 2008, Pesticides in urban surface water: Annual review of new scientific findings 2008, 32 p.

van der Hoff, G.R., Pelusio, F., Brinkman, U.A.T., Baumann, R.A., and van Zoonen, P., 1996, Automated solid-phase extraction coupled to gas chromatography with electroncapture detection: A combination of extraction and clean-up of pyrethroids in the analysis of surface water: Journal of Chromatography A, v. 719, p. 59-67.

Ward, J.R., and Harr, C.A., eds., 1990, Methods for collection and processing of surface-water and bed-material samples for physical and chemical analyses: U.S. Geological Survey Open-File Report 90-140, 71 p.

Wheelock, C.E., Miller, J.L., Miller, M.J., Phillips, B.M., Gee, S.J., Tjeerdema, R.S., and Hammock, B.D., 2005, Influence of container adsorption upon observed pyrethroid toxicity to Ceriodaphnia dubia and Hyalella azteca: Aquatic Toxicology, v. 74, p. 47-52.
U.S. Geological Survey, 2006, Collection of water samples (ver. 2.0): U.S. Geological Survey Techniques of WaterResources Investigations, book 9, chap. A4, accessed October 7, 2008, at http://pubs.water.usgs.gov/twri9A4/

Zhou, J.L., Rowland, S., and Mantoura, R.F.C., 1995, Partition of synthetic pyrethroid insecticides between dissolved and particulate phases: Water Resources, v. 29, p. 1023-1031.

Zhou, J.L., Rowland, S.J., Mantoura, R.F.C., and Lane, M.C.G., 1997, Desorption of tefluthrin insecticide from soil in simulated rainfall runoff systems-kinetic studies and modeling: Water Resources, v. 31, p. 75-84. 


\section{Appendix}

Standard Operating Procedure for Sampling Pyrethroid Insecticides in Water and Sediment

Prepared by: Michelle Hladik

Reviewed by: Lisa Olsen

Approved by: Keith Kirk
Date: August 6, 2008

Date: August 25, 2008

Date: January 14, 2009

UNITED STATES GEOLOGICAL SURVEY

CALIFORNIA WATER SCIENCE CENTER 
Pyrethroid Sampling

Rev 1.0

Date: $02 / 09$

Page 1 of 7

\section{Table of Contents}

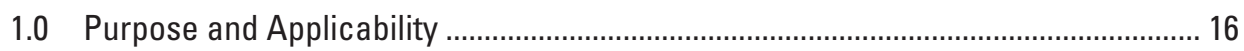

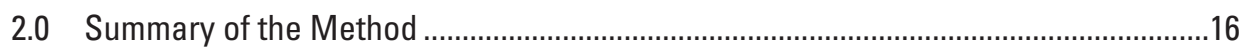

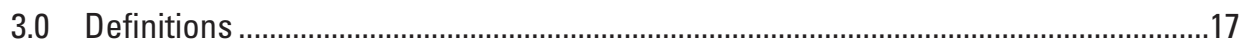

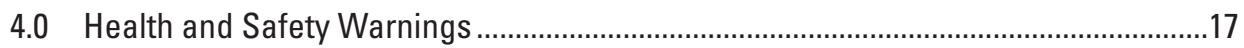

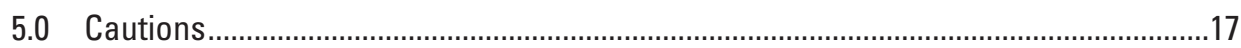

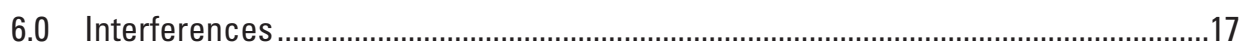

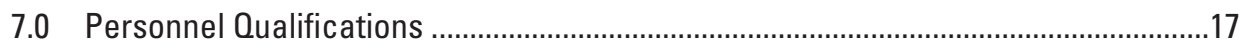

8.0 Equipment and Supplies ....................................................................................

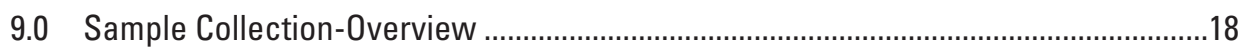

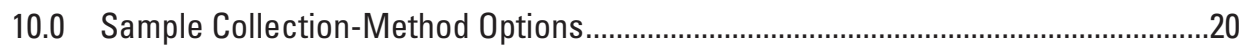

11.0 Sample Handling and Preservation ......................................................................21

12.0 Quality Assurance and Quality Control ..................................................................22

\section{Procedures}

\subsection{Purpose and Applicability}

The purpose of this Standard Operating Procedure (SOP) is establish guidelines for the collection and handling of water and sediment samples that will be analyzed for pyrethroid insecticides. The procedures outlined are designed to be used as a general guide for pyrethroid sample collection; pyrethroids are more hydrophobic than other current-use pesticides and require that specific steps be taken to ensure that representative results are obtained. This SOP is intended to supplement other documents that describe how to collect water and sediment samples: for example, the USGS National Field Manual for the Collection of Water-Quality Data, or comparable methods.

\subsection{Summary of the Method}

Due to their hydrophobicity, pyrethroid insecticides may adhere to sampling equipment, sample containers, as well as to laboratory analysis and testing equipment. Losses from environmental samples to these materials may be as high as 50 percent, biasing results. The tendency of pyrethroids to adhere to the surfaces of containers and equipment varies depending on the container material, the volume-to-contact-area ratio, and the water matrix composition (concentrations of dissolved organic carbon and suspended sediment). Minimizing the loss of pyrethroids during sampling, storage and processing is accomplished most effectively by using equipment and containers made out of glass, stainless steel, or plastic (low-density polyethylene [LDPE] or high-density polyethylene [HDPE]); Teflon can be used if the sample is kept flowing or sits for less than 1 hour. Shaking the sample vigorously immediately prior to transferring to a different container or for analysis or by maintaining a continuous flow of water through the sampling apparatus, and sub-sampling from equipment and containers that have a high sample volume-tocontact-area ratio, will also help to minimize the loss of pyrethroids.

Sampling situations vary widely, but this SOP encompasses many procedures commonly used by field personnel. 
Pyrethroid Sampling

Rev 1.0

Date: $02 / 09$

Page 2 of 7

\subsection{Definitions}

1. Pyrethroid: any of various synthetic compounds that are related to the pyrethrins and resemble them in insecticidal properties.

\subsection{Health and Safety Warnings}

Persons who collect samples should treat all sources of sample water and sediment as though they contained chemical or biological agents that could cause illness or harm. The sampler should wear protective gloves, at a minimum, and additional safety gear as necessary. Personnel collecting samples should wear U.S. Coast Guard approved personal floatation devices when working on or near the water. Samples are often collected from bridges, and personnel should be aware of road traffic and exercise appropriate traffic control procedures.

\subsection{Cautions}

Organic solvents may be used during the processing of samples. Standard laboratory safety procedures, as well as specific safety information contained in the Material Safety Data Sheets for these chemicals, must be followed.

\subsection{Interferences}

The purpose of representative sampling is to characterize the true concentrations of constituents of concern (in this case pyrethroid insecticides) in environmental samples. Unintended sample contamination is a point of concern, and steps must be taken to limit it. Sampling equipment and sample containers must be cleaned thoroughly prior to sampling. For water samples, containers should be rinsed three times with site water prior to collecting the sample. Pyrethroid insecticides are a common ingredient in household pesticide products. Field personnel should be aware of this and limit their exposure to these products prior to sample collection. To further confirm that there is no unintended sample contamination, field blanks must be included.

Because of the hydrophobicity of pyrethroids, particular attention should be given to materials used in sampling equipment, sample containers, and items that may come into contact with samples during laboratory analysis and testing.

\subsection{Personnel Qualifications}

This SOP is written for a wide audience. Personnel should have proper training in field sample collection, sample handling and laboratory processing techniques, as mandated by their respective organizations.

\subsection{Equipment And Supplies}

Equipment needed for the collection of pyrethroids in water samples may include:

- Glass, plastic (HDPE or LDPE), or Teflon bottles

- Sampling nozzles for US D-95 and US D-96 samplers

- US D-95 isokinetic depth-integrating sampler 
Pyrethroid Sampling

Rev 1.0

Date: $02 / 09$

Page 3 of 7

- US D-96 isokinetic depth-integrating sampler

- Teflon bags for D-96 sampler

- Teflon churn

- Stainless-steel soda kegs

- Autosampler (ISCO)

- Pump capable of flow rates greater than $500 \mathrm{~mL} / \mathrm{min}$

- Pump tubing (Teflon or stainless steel)

- Ice

- Coolers (and packing equipment)

- Chain-of-custody forms, field data sheets, field notebook

- Cleaning reagents, including pesticide grade methanol

- Sample-container labels

- Approved QA project plan

- Approved field health and safety plan

Equipment needed for the collection of pyrethroids associated with sediments includes:

- Glass jars

- Stainless-steel scoop or spoon

- Ice

- Coolers (and packing equipment)

- Chain-of-custody forms, field data sheets, field notebook

- Cleaning reagents

- Sample container labels

- Approved QA project plan

- Approved field health and safety plan

\subsection{Sample Collection-Overview}

General sampling methods for the collection of water and sediment samples are beyond the scope of this document. It is recommended that personnel follow the standard sample-collection, quality-assurance/quality-control (QA/QC), and equipment-cleaning procedures required by their respective agencies. This document pertains solely to the collection of samples to be analyzed for pyrethroid pesticides, which require that certain equipment and sample containers be used and that additional sample handling guidelines be followed as outlined below. A summary of the loss of pyrethroids to sampling apparatuses tested is detailed in table A1. 
Pyrethroid Sampling

Rev 1.0

Date: $02 / 09$

Page 4 of 7

1. Sampling equipment components (housings, pump heads, tubing, etc.) that come into contact with the sample should be constructed of stainless steel, glass, plastic (LDPE or HDPE) or Teflon.

2. When samples are collected using an automatic sampler or pump, input and output lines should be flushed a minimum of three times (flow rate greater than $500 \mathrm{~mL} / \mathrm{min}$ ) with sample water, equal to the total volume of the sampling lines, immediately prior to sample collection. This is in addition to any standard cleaning procedures conducted prior to the initial sampling.

3. Sample containers should be constructed of stainless steel, glass, or plastic (HDPE or LDPE). Use containers that are the appropriate size for the volume of sample to be collected to minimize the amount of surface area to which the sample is exposed.

4. Do not store samples for longer than 1 hour in containers made of Teflon.

5. Immediately prior to transferring sample water from equipment (sampler, churn, etc.) or a container, shake the sample water vigorously for a minimum of one minute. If the transfer takes longer than a few minutes, shake the sample continuously during the process. These procedures are not required for sediment samples.

Table A1. Range of percent loss to containers of 14 pyrethroid compounds spiked in environmental samples and exposed to various sampling equipment/container materials.

[Agitated samples were shaken vigorously for 1 minute or run through a pump system immediately prior to water removal and testing. i.d., inner diameter; LDPE, low-density polyethylene. L, liter; hr, hour; mm, millimeter; L/min, liter per minute. Values given in percent]

\begin{tabular}{|c|c|c|}
\hline Sampler/container description & $\begin{array}{c}\text { Pyrethroids range of } \\
\text { percent loss to containers } \\
\text { (not agitated) }\end{array}$ & $\begin{array}{l}\text { Pyrethroids range of } \\
\text { percent loss to containers } \\
\text { (agitated) }\end{array}$ \\
\hline Glass 1-L bottle (stored 24 hrs) & $4-31$ & $2-4$ \\
\hline Teflon 1-L bottle (stored $1 \mathrm{hr}$ ) & Not tested & $2-8$ \\
\hline Teflon 1-L bottle (stored $24 \mathrm{hrs)}$ & $4-31$ & $2-21$ \\
\hline Teflon 3-L bag (stored $1 \mathrm{hr}$ ) & Not tested & $2-10$ \\
\hline Teflon churn (3 L of water, stored $1 \mathrm{hr}$ ) & Not tested & $2-16$ \\
\hline Teflon churn ( $8 \mathrm{~L}$ of water, stored $1 \mathrm{hr}$ ) & Not tested & $3-7$ \\
\hline LDPE Cubitainer ${ }^{\circledR} 4$ L (stored 7 days) & Not tested & $0-8$ \\
\hline LDPE Cubitainer@ 19 L (stored 7 days) & Not tested & $0-4$ \\
\hline Stainless steel keg $20 \mathrm{~L}$ (stored $24 \mathrm{hrs}$ ) & Not tested & $1-4$ \\
\hline Stainless steel filter housing ${ }^{1}$ & Not tested & $2-6$ \\
\hline ISCO automatic sampler ${ }^{2}$ & Not tested & 0 \\
\hline Glass 500-milliliter sediment jars ${ }^{3}$ & $0-2$ & Not tested \\
\hline
\end{tabular}


Pyrethroid Sampling

Rev 1.0

Date: 02/09

Page 5 of 7

\subsection{Sample Collection-Method Options}

\subsection{Water}

\subsubsection{Grab Sample}

A grab sample is appropriate in situations where the waters to be sampled are known to be well-mixed and where flow rates are nearly uniform both laterally and vertically.

1. Use a 1-L amber glass bottle that has been baked at $450^{\circ} \mathrm{C}$ for 4 hours, or a plastic (LDPE or HDPE) or Teflon container that has been solvent-rinsed with methanol.

2. Rinse the container three times with water to be sampled.

3. Fill the container to at least the shoulder of the bottle with the sampled water.

4. Cap the container and place on ice.

\subsubsection{Isokinetic Depth-Integrated Sample}

An integrated sample is appropriate in situations where the waters to be sampled are not well-mixed in terms of water-quality characteristics and/or flow.

1. Use an approved isokinetic, depth-integrating sampler such as a US D-95, or US D-96 (Lane and others, 2003).

2. The sample container should be solvent-cleaned with pesticide-grade methanol.

3. Rinse sampler and container three times with water to be sampled.

4. Collect the water sample using appropriate techniques.

5. Do not store the sample for longer than 1 hour in Teflon containers. After sampling, shake bottle vigorously for 1 minute and transfer to a glass container.

6. Cap the container and place on ice.

\subsubsection{Large-Volume Sample}

Large-volume water samples ( $>4 \mathrm{~L}$ ) are typically collected using a pump and tubing apparatus, commonly for the isolation of large amounts of suspended sediments or for toxicity testing.

1. Pump parts and tubing exposed to sample water should be constructed of Teflon or stainless steel, and cleaned with methanol prior to sampling. Sample water equal to three times the volume capacity of the pump and tubing should be rinsed through the equipment prior to collecting a sample, and water must be pumped at a flow rate of $500 \mathrm{~mL} / \mathrm{min}$.

2. Sample water should be pumped into containers constructed of stainless steel or plastic (LDPE and HDPE), which have been cleaned with methanol. 
Pyrethroid Sampling

Rev 1.0

Date: $02 / 09$

Page 6 of 7

\subsubsection{Autosampler}

An autosampler is useful for situations where multiple samples must be collected over a period of time (for example, a storm event), or in situations were sampling is initiated automatically by a change in stream stage.

1. Pump parts and tubing exposed to sample water should be constructed of Teflon or stainless steel, and cleaned with methanol prior to any collection of samples. The autosampler should be set to sample water equal to three times the volume capacity of the pump and tubing. Water must be pumped at a flow rate of $500 \mathrm{~mL} / \mathrm{min}$.

2. Sample water should be pumped into glass bottles in the autosampler that have been baked at $450^{\circ} \mathrm{C}$ for 4 hours.

\subsection{Sediment Sample}

Sediment samples generally are collected as multiple individual grab samples and later composited (Radtke, 2005).

1. Sediments should be collected using equipment constructed of glass or stainless steel.

2. After collection, sediment samples should be transferred to glass containers that have been baked at $450^{\circ} \mathrm{C}$ for 4 hours and then allowed to cool to room temperature.

3. Cap the container and place on ice.

\subsection{Sample Handling and Preservation}

\subsection{Sample Holding}

1. Water samples should be held in glass containers at $4^{\circ} \mathrm{C}$ until analysis. Samples should be analyzed within 3 days of collection.

2. Sediment samples should be held in glass containers at $-20^{\circ} \mathrm{C}$ until analysis. Samples should be held for a maximum of 6 months prior to analysis. Leave adequate headspace for expansion during freezing.

\subsection{Sample Handling}

1. Water samples must be agitated vigorously by hand for 1 minute prior to transferring, filtering, or compositing.

2. For dissolved water samples, the water should be filtered through a diaphragm pump with a Teflon-lined pumphead, $1 \mathrm{~m}$ of 5 - $\mathrm{mm}$ i.d. Teflon tubing, $150 \mathrm{~mm}$ of glass-fiber filter (pre-baked at $450^{\circ} \mathrm{C}$ for 4 hours), flow rate of $0.5 \mathrm{~L} / \mathrm{min}$. Filtration should happen as soon as possible after sample collection (in the field, if possible).

3. If water samples are being composited, this should be done through a Teflon churn. Sample water should be agitated continuously during compositing, and sample water should not be stored in the churn for more than 1 hour prior to compositing.

4. Sediment samples should be composited using stainless-steel equipment that has been cleaned with methanol. 
Pyrethroid Sampling

Rev 1.0

Date: 02/09

Page 7 of 7

\subsection{Quality Assurance and Quality Control}

Given the tendency of pyrethroid pesticides to adhere to equipment/container surfaces, QA/QC samples are an essential tool used to characterize sample contamination, pyrethroid carryover between samples, and the loss of pyrethroids to equipment/container surfaces. Field, equipment, and laboratory blank samples as well as field and laboratory replicate samples and matrix-spike samples should be collected in accordance with standard QA/QC guidelines. 
Manuscript approved for publication, January 14, 2009

Prepared by the USGS Publishing Network,

Publishing Service Center, Sacramento, California

Susan Davis

Yvonne Roque

Carol Sanchez

For more information concerning the research in this report, contact the California Water Science Center Director,

U.S. Geological Survey, 6000 J Street

Sacramento, California 95619

http://ca.water.usgs.gov 


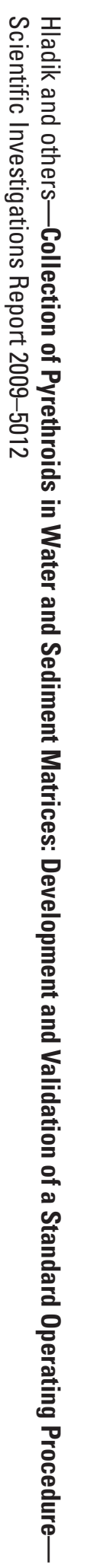

8 Printed on recycled paper 